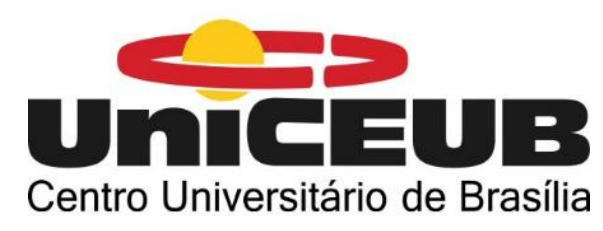

CENTRO UNIVERSITÁRIO DE BRASÍLIA-UnICEUB PROGRAMA DE INICIAÇÃO CIENTIFICA

IGOR E SILVA AGUIAR

DETECÇÃO MOLECULAR DE RIQUÉTSIAS COM LEVANTAMENTO ACAROLÓGICO EM EQUINOS CAPTURADOS NO DISTRITO FEDERAL, BRASIL

BRASÍLIA

2020 


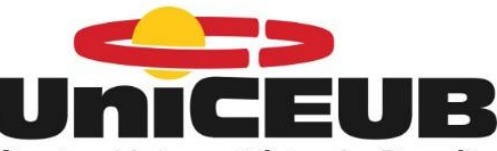 \\ Centro Universitário de Brasília}

IGOR E SILVA AGUIAR

\section{DETECÇÃO MOLECULAR DE RIQUÉTSIAS COM LEVANTAMENTO ACAROLÓGICO EM EQUINOS CAPTURADOS NO DISTRITO FEDERAL, BRASIL}

Relatório final de pesquisa de Iniciação Científica apresentado à Assessoria de PósGraduação e Pesquisa.

Orientação: Bruno Silva Milagres

BRASÍLIA 


\section{Agradecimentos}

Agradeço ao meu professor orientador Bruno Silva Milagres, pela orientação apoio e confiança. Que sempre se dispôs e se prontificou a dar auxílio e muita atenção durante o desenvolvimento do projeto.

Ao professor Francisco José Gonçalves de Oliveira, por fornecer animais de seu haras para coleta de carrapatos, que certamente auxiliou no desenvolvimento do projeto.

Ao meu amigo e colega de curso Mateus Braga Carvalho que esteve comigo em momentos de coleta e se prontificou a auxiliar no que fosse preciso durante a fase prática do projeto.

A todos que contribuíram de forma direta ou indireta no desenvolvimento do trabalho. 


\section{DETECCÃO MOLECULAR DE RIQUÉTSIAS COM LEVANTAMENTO ACAROLOGICO EM EQUINOS CAPTURADOS NO DISTRITO FEDERAL, BRASIL}

\section{RESUMO}

A Febre Maculosa Brasileira é uma doença causada por bactérias do gênero Rickettsia, transmitidas através da picada e adesão de carrapatos contaminados ao hospedeiro, sendo relatado tempo mínimo de adesão para contaminação de 15 minutos. Os principais carrapatos vetores da FMB são Amblyomma cajennense, Amblyomma aureolatum, Amblyomma dubitatum e Amblyomma ovale, mas qualquer espécie pode ser reservatório de $R$. rickettssii. Esses vetores podem parasitar também antas, roedores, aves, capivaras, serpentes, morcegos, peixes, gambás, cães, gatos e equinos, que por sua vez, podem ser multiplicadores de Rickettsia rickettssii, exercendo um papel importante no aumento da virulência. O objetivo do trabalho foi fazer uma revisão bibliográfica, sobre os dados epidemiológicos no brasil dos anos de 2017 e 2018, onde em, 2017 foram encontrados 189 casos e em 2018 foram encontrados 62 casos. Sendo desses casos a sua maior concentração na região sudeste e em regiões rurais, atingindo principalmente homens, na faixa etária entre 20 e 59 anos de idade. A letalidade varia de $34 \%$ em 2017 a $25 \%$ em 2018, letalidade alta em relação aos outros agravos. Diante disso, para uma boa prevenção, se dá evitando o contato com o vetor, assim usando roupas que cobrem o corpo, e usando uma proteção química como repelentes tanto nos equinos quanto nas pessoas. Há uma necessidade de um estudo aprofundado na região do centrooeste que possui reservatórios e vetores da Rickettsia, para um melhor entendimento epidemiológico dos carrapatos. A divulgação da importância da prevenção e do tratamento da FMB pode influenciar numa diminuição da letalidade pela doença.

Palavras chaves: rickettsia/ epidemiologia/ equinos 
LISTA DE SÍMBOLOS, SIGLAS E ABREVIATURAS …................................ 6

LISTA DE GRÁFICOS, TABELAS E IMAGENS …...................................... 7

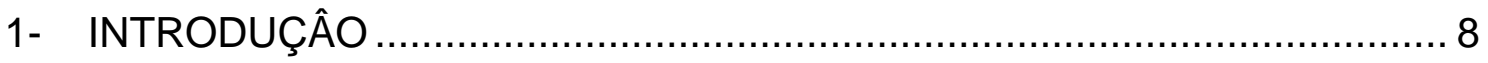

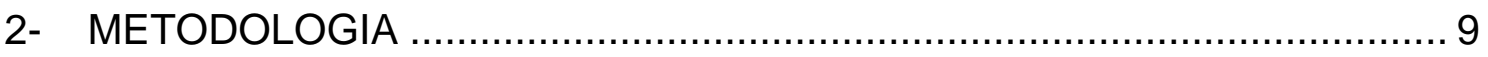

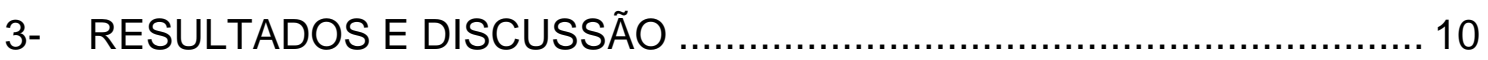

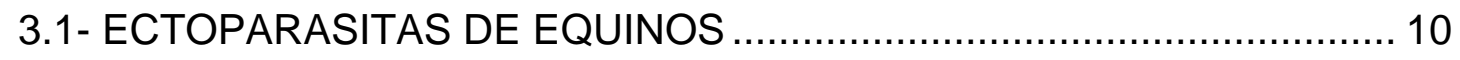

3.2- PERFIL EPIDEMIOLÓGICO DA FEBRE MACULOSA ......................... 10

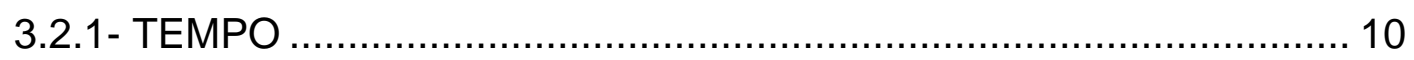

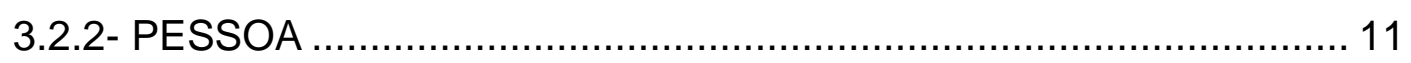

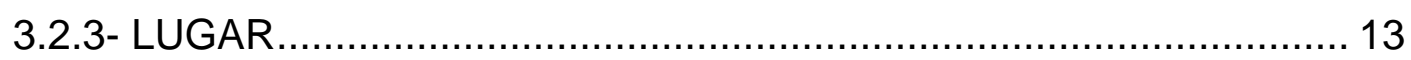

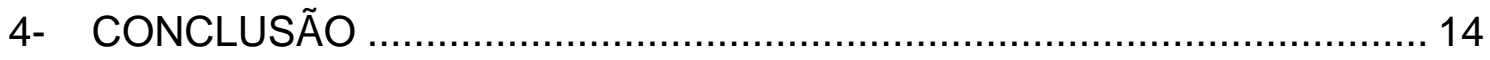

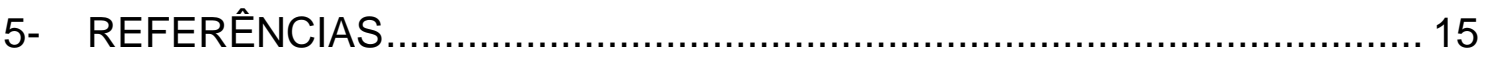




\section{LISTA DE SÍMBOLOS, SIGLAS E ABREVIATURAS}

FMB - Febre Maculosa brasileira.

SEAGRI-DF - Secretaria de Estado de Agricultura, Abastecimento e Desenvolvimento Rural do Distrito Federal gltA - proteína de membrana da bactéria.

DNA - Ácido desoxirribonucleico.

D. nitens - Dermacentor nitens 


\section{LISTA DE GRÁFICOS E TABELAS}

Gráfico 1: Mês de confirmação de casos de FMB.

Gráfico 2: Faixa etária de casos confirmados de FMB em 2017.

Gráfico 3: Casos confirmados de homens e mulheres em 2017.

Gráfico 4: Zona de infecção de casos confirmados da FMB.

Tabela 1: Taxa de letalidade, mortalidade e morbidade da FMB nos anos de 2017 e 2018.

Tabela 2: Dados de febre maculosa 2018. 


\section{1- INTRODUÇÂO}

A Febre Maculosa Brasileira (FMB) é uma doença causada por bactérias do gênero Rickettsia, transmitidas através da picada e adesão de carrapatos contaminados ao hospedeiro, sendo relatado tempo mínimo de adesão para contaminação de 15 minutos. As riquétsias mais associadas à febre maculosa no Brasil são a Rickettsia rickettssii e a Rickettsia sp. cepa Mata Atlântica, a primeira relacionada a casos graves da doença, mais comumente encontrada nas regiões Sul e Sudeste, e a segunda, presente no Sul, Sudeste e Nordeste, causa uma forma mais branda da doença (OLIVEIRA, 2017). Apesar desses achados, tem-se observado baixa frequência de suspeição clínica e epidemiológica de casos de febre maculosa na Região Norte e parte das Regiões Nordeste e Centro-Oeste, consideradas áreas silenciosas para o agravo (OLIVEIRA, 2016b). Nessas áreas o conhecimento sobre a história natural e da distribuição de riquetsioses de interesse médico ainda é incipiente. Segundo Milagres (2010), o avanço na área da Biologia Molecular tem favorecido a obtenção de conhecimentos a respeito dessas bactérias, permitindo a identificação de novas espécies, no entanto, por aparentemente não apresentarem riscos para o ser humano, nem todas são tratadas com a devida atenção.

Os principais carrapatos vetores da FMB são Amblyomma cajennense, Amblyomma aureolatum, Amblyomma dubitatum e Amblyomma ovale, mas qualquer espécie pode ser reservatório de $R$. rickettssii (ARAÚJO; NAVARRO; CARDOSO, 2016; OLIVEIRA, 2016a). Esses vetores podem parasitar também antas, roedores, aves, capivaras, serpentes, morcegos, peixes, gambás, cães, gatos e equinos, que por sua vez, podem ser multiplicadores de Rickettsia rickettssii, exercendo um papel importante no aumento da virulência. A presença de numerosas populações desses vetores e desses animais multiplicadores é um achado comum nas áreas endêmicas para FMB (ARAÚJO; NAVARRO; CARDOSO, 2016; MILAGRES, 2010). 


\section{2- METODOLOGIA}

Para o estudo dos vetores e seus agentes causadores de doenças, este foram baseados em busca na literatura sobre os principais vetores e associações com equinos. A busca na literatura foi realizada por meio de consultas as bases as bibliotecas eletrônicas Scientific Electronic Library Online (SciELO) e nas bases de dados Literatura Latino-Americana e do Caribe (LILACS). A busca das publicações foi guiada pela combinação dos descritores supracitados, usados isoladamente ou combinados com os buscadores Booleanos (AND e OR): ectoparasitas, carrapatos, febre maculos, equinos, saúde pública e seus correspondentes em espanhol e inglês. Ademais, também foram consultadas as publicações do Ministério da Saúde, incluindo seus boletins epidemiológicos.

Os ectoparasitas foram coletados dos equinos capturados e apreendidos pela Secretaria de Estado de Agricultura, Abastecimento e Desenvolvimento Rural do Distrito Federal - SEAGRI-DF, esses após a apreensão realizado a busca manuais e acondicionados em potes coletores e doados aos pesquisadores deste projeto.

Os ectoparasitas coletados e doados pela SEAGRI-DF, foram encaminhados ao laboratório e possível identificação taxonômica que serão identificados de acordo com a chave dicotômica e pictórica descrita por Aragão \& Fonseca (1961) e separados segundo gênero, sexo e estádio de desenvolvimento e armazenados.

Eles serão encaminhados para 0 Laboratório de Parasitologia e Epidemiologia Molecular do Departamento de Bioquímica e Biologia Molecular da Universidade Federal de Viçosa, para a sua confirmação taxonômica e para desenvolvimento de trabalhos posteriores para o diagnóstico de Rickettsia através da técnica de biologia Molecular, após o período de pandemia e a volta das atividades das universidades federais.

Com relação aos aspectos éticos, por se tratar de um estudo baseado em dados secundários e havendo apenas doação de ectoparasitas da população de equinos estudada, não se faz necessário a provação do comitê de ética. 


\section{3- RESULTADOS E DISCUSSÃO}

\section{1- ECTOPARASITAS DE EQUINOS}

Amblyomma cajennense é um carrapato de distribuição geográfica muito ampla, e tem uma peculiaridade de ser na verdade um conjunto de seis espécies de carrapato sendo elas, Amblyoma mixtum, Amblyoma sculptum, Amblyoma tonelliae, Amblyoma interandinum e Amblyoma patinoi. Todas têm ampla distribuição geográfica pelo mundo e no brasil ocorre apenas duas dessas espécies, a Amblyoma sculptum acaba sendo a espécie de maior distribuição pelo território brasileiro. Trata-se esses carrapatos como os principais vetores da FMB, que também acomete humanos, pela bactéria Rickettsia rickettsii, sua transmissão pode ocorrer em qualquer fase de vida do vetor (RODRIGUES et, al 2015).

Dermacentor nitens é uma espécie de carrapatos que ocorre em equinos, é conhecido como o "carrapato da orelha do cavalo", mas com um alto grau de infestação ele pode ser encontrado em qualquer região do corpo de um equino. A grande ocorrência de infestações altas deste carrapato, geralmente acontece em propriedades que tem o foco em equinos, e pode causar uma queda na produtividade. Esse carrapato é mais encontrado na região sudeste do brasil, suas maiores infestações ocorrem no primeiro semestre do ano, sendo que há uma baixa no mês de agosto e retorna no mês seguinte (KOLLER et, al 2017).

Como todo parasita hematófago, ou seja, que se alimenta de sangue, ainda mais em espécies que necessitam de mais de um hospedeiro, acabam se tornando vetores de algumas doenças, pelo ato de mudar de hospedeiro. Portanto $\circ D$. nitens se alimenta em um único hospedeiro, sendo assim a transmissão de doenças acontece de forma diferenciada. Primeiramente um carrapato mãe infectado faz a transmissão transovariana, para os ovos. Então em seguida acontece a transmissão entre estágios até a fase adulta, quando 0 carrapato poderá passar para sua prole o patógeno que ele porta. Entre esses patógenos podemos citar o da babesiose equina, também conhecida como piroplasmose que é causada pelo protozoário Babesia caballi, sendo que tanto larvas, ninfas e adultos são vetores eficazes. Também tem a FMB que é causada pela bactéria Rickettsia rikettsii e outras bactérias do grupo da febre maculosa pode ser encontrada no carrapato (KOLLER et, al 2017).

\section{2- PERFIL EPIDEMIOLÓGICO DA FEBRE MACULOSA}

\subsection{1- TEMPO}

É possível perceber que há um aumento de casos de FMB no brasil no período de julho a novembro, porém os carrapatos que transmitem a FMB possuem uma boa sazonalidade por possuir três fases e cada uma pode acontecer em um hospedeiro, sendo que nas trocas de faze, ele passa por um processo de ecdise. Por ser sazonal, seu ciclo reprodutivo ocorre o ano inteiro, sendo que em temperaturas mais quentes é encontrado carrapatos adultos a 
partir do mês de julho, o que corrobora com o (Gráfico 1) que mostra onde foi possível perceber um aumento de casos de FMB a partir do mês de julho (MONTEIRO, 2010; MARTINS, 2014).

Gráfico 1: Mês de confirmação de casos de FMB.

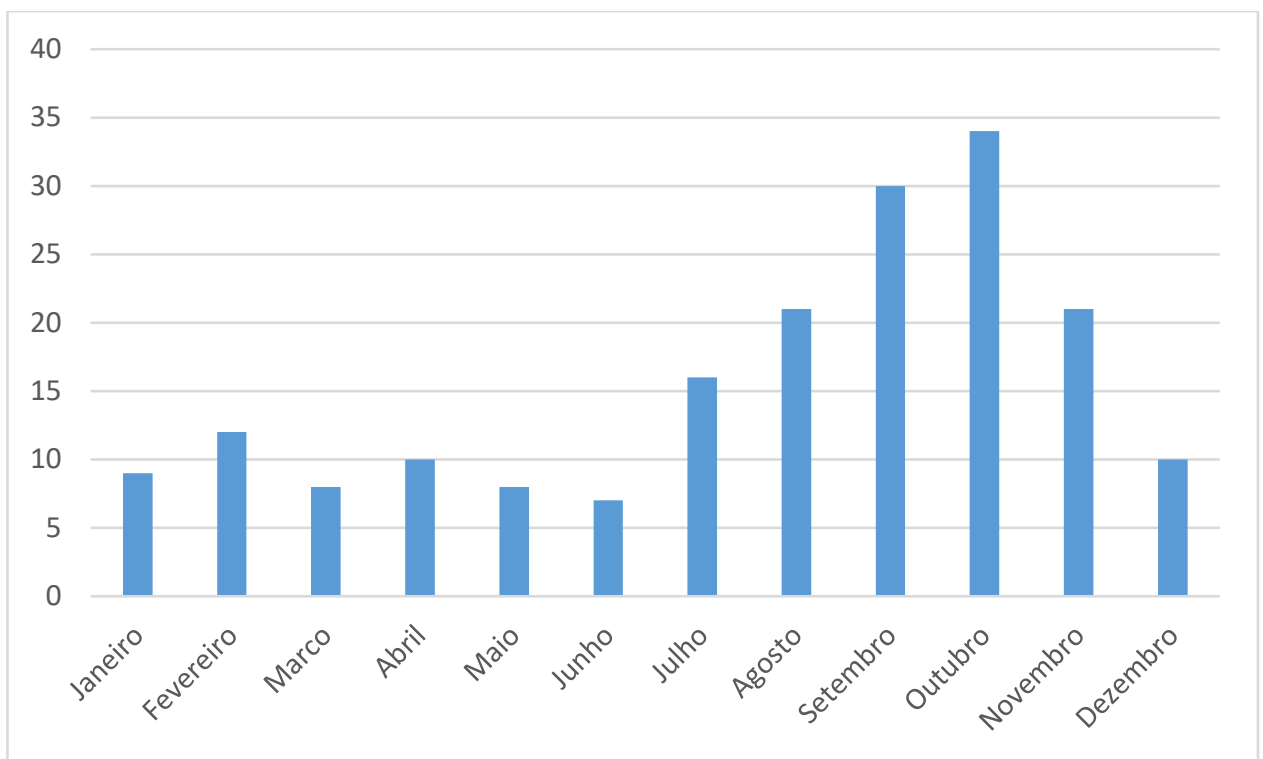

Fonte: Brasil, 2020.

\subsection{2- PESSOA}

Para o entendimento de como foi a epidemiologia da FMB nos anos de 2017 e 2018, foi realizado um estudo de dados fornecidos pelo SINAN estabelecendo as taxas de mortalidade, letalidade e morbidade como mostra a (Tabela 1). É possível perceber que a faixa etária entre 20 e 59 anos (Gráfico 2), tem um maior número de casos confirmados, isso pode ser pelo fato dessa idade estar relacionada a jornada de trabalho da população brasileira, com isso, é possível a associação ao (Gráfico 4), onde é observado que a maior zona de infecção está aglomerado na zona rural, onde geralmente homens, nessa faixa de idade (Gráfico 3), estão trabalhando nos campos.

Tabela 1: Taxa de letalidade, mortalidade e morbidade da FMB nos anos de 2017 e 2018.

2017

2018

\begin{tabular}{|ccc|}
\hline MORTALIDADE & 31 a cada $100 \mathrm{mi}$. & 7 a cada $100 \mathrm{mi}$. \\
\hline LETALIDADE & 34 a cada 100 casos. & 25 a cada 100 casos. \\
MORBIDADE & 9 a cada $10 \mathrm{mi}$. & 2,9 a cada $10 \mathrm{mi}$.
\end{tabular}

Mi: milhões de brasileiros.

Fonte: O globo, 2018. 
Gráfico 2: Faixa etária de casos confirmados de FMB em 2017.

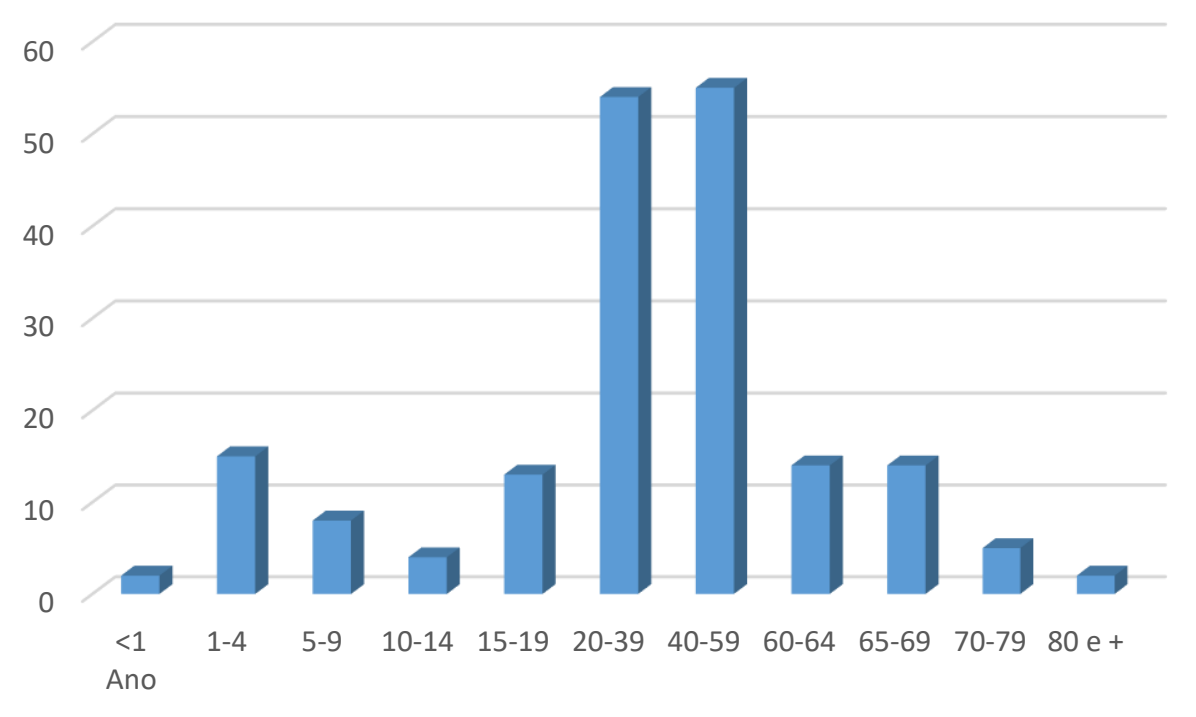

Fonte: Brasil, 2020.

Gráfico 3: Casos confirmados de homens e mulheres em 2017.

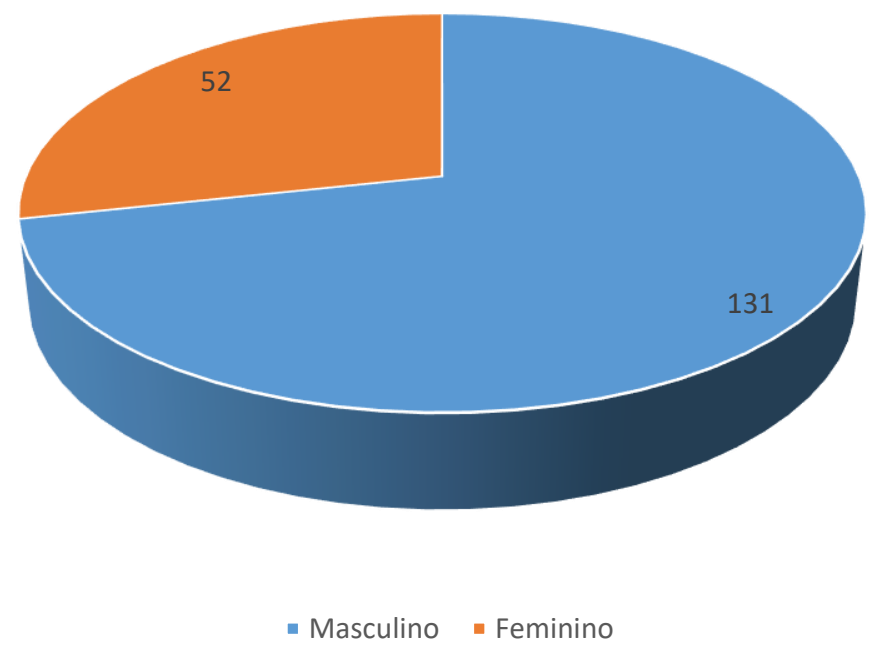

Fonte: Brasil, 2020. 
Gráfico 4: Zona de infecção de casos confirmados da FMB.

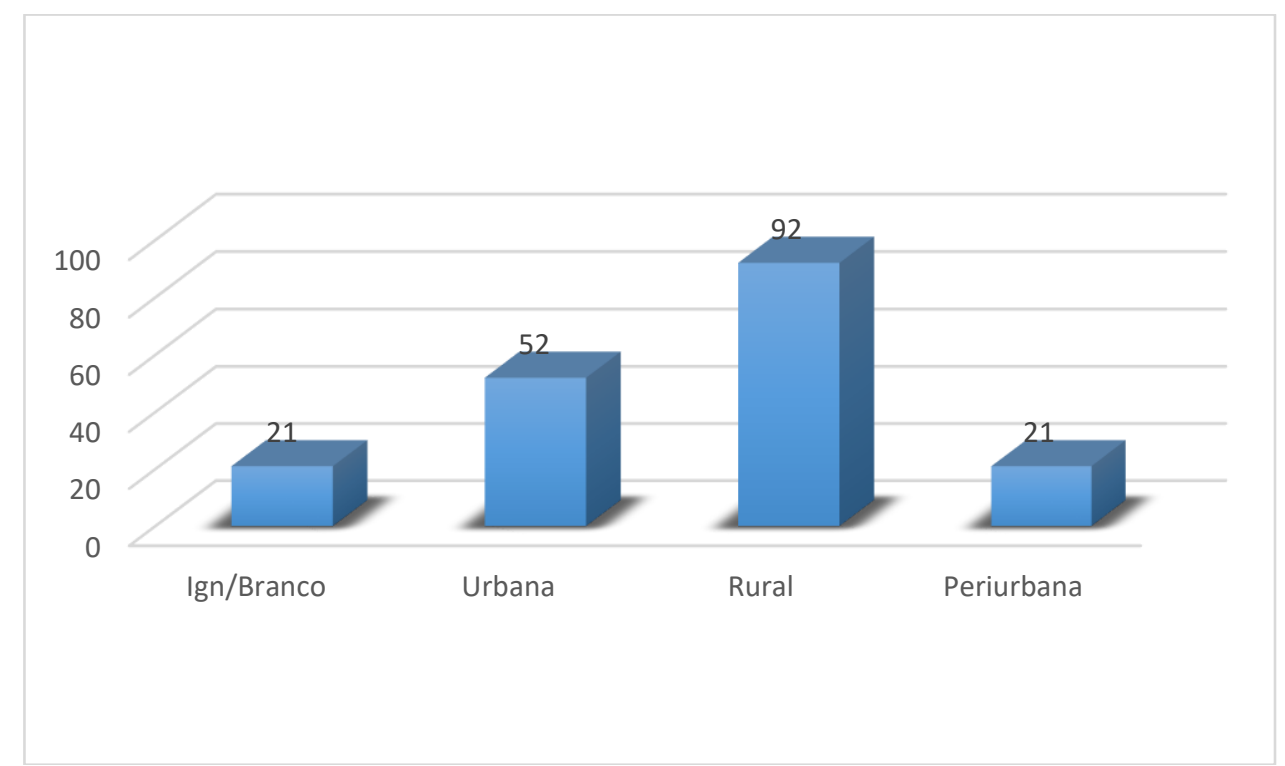

Fonte: Brasil, 2020.

\subsection{3- LUGAR}

O sudeste é a região com maior número de casos notificados, como observado na (Tabela 2), isso se dá por ser uma região com população densa, com municípios e áreas rurais que possuem grandes áreas plantadas, o que interfere diretamente no potencial de disseminação da FBM (BRASIL, 2019). Não se sabe ao certo qual a interferência do clima na alta quantidade de casos de febre maculosa, pelo sudeste ser uma região com alta variabilidade climática (RIBEIRO et, al. 2013).

Tabela 2: Dados de febre maculosa 2018.

\begin{tabular}{lllr}
\hline Região & Estados / Número de casos & Total de casos \\
\hline Norte & Pará 1 & 1 \\
\hline Nordeste & Maranhão 2 & Alagoas 1 & 3 \\
\hline Sudeste & Minas Gerais 10 & São Paulo 33 & 43 \\
\hline Sul & Santa Catarina 12 & \\
\hline Centro-oeste & Mato Grosso do Sul 1 & 1 \\
\hline Brasil & & 60 \\
\hline Fonte Sinan, 2018.
\end{tabular}




\section{4- CONCLUSÃO}

Conclui-se que após observar esses dados, existe uma boa circulação, de bactérias do gênero das Rikketsias em áreas rurais por ter a maior concentração de casos confirmados. Para evitar de contrair a FMB deve-se evitar de entrar em contato com o vetor, ou seja, ao andar no campo ou em regiões que tem muitos carrapatos, é importante estar de roupas adequadas, como botas, luvas e roupas q cubram o corpo. Para ajudar os equinos a terem menos infestações de carrapatos, o uso de shampoos repelentes que, de certa forma, também ajuda no controle vetorial, o uso de repelentes em humanos também é benéfico, por ajudar a evitar esse contato.

Outrossim, possivelmente o número de casos confirmados acabaria diminuindo e auxiliaria a manter o ciclo do carrapato incompleto pois ele precisa de hospedeiros finais para terminar o ciclo. O sucesso disso pode ajudar na manutenção populacional dos carrapatos pois grande parte deles, ao não chegar a completar o ciclo, ajudaria a diminuir os casos da FMB no brasil.

Cabe ressaltar que a FMB, na região do centro-oeste, tem a existência de carrapatos e seus reservatórios, porém não há artigos falando desta região, com isso têm a necessidade de novos estudos sobre a questão epidemiológica dos carrapatos. Dessa forma a população deve ser informada da importância do diagnóstico precoce e do tratamento contra a $\mathrm{FMB}$, pois, apesar do número de casos ser baixo, a letalidade é alta comparada a outras infecções. 


\section{5- REFERÊNCIAS}

ARAUJO, R.P.; NAVARRO, M. B. M. A.; CARDOSO, T. A. O. Febre maculosa no Brasil: estudo da mortalidade para a vigilância epidemiológica. Caderno de saúde coletiva, Rio de Janeiro, v. 24, n. 3, p. 339-346, Set 2016.

KOLLER, WILSON WERNER. et. al. Biologia e controle de Dermacentor nitens: o carrapato-da-orelha-do-cavalo. Embrapa gado de corte, v.21, jul. 2017. Disponível em: <http://www.cnpgc.embrapa.br/publicacoes/doc/DOC231.pdf>. Acesso em: 23 out. 2020.

LABRUNA, M. B. et al. Rickettsia Species Infecting Amblyomma cooperi Ticks from an Area in the State of Sao Paulo, Brazil, Where Brazilian Spotted Fever Is Endemic. J. Clin. Microbiol., v.42, n.1, p.90-98, January 2004.

MARTINS, G.P. DETECÇÃO SOROLÓGICA DE RIQUÉTSIAS DO GRUPO DA FEBRE MACULOSA E LEVANTAMENTO ACAROLÓGICO EM EQUINOS NO DISTRITO FEDERAL, BRASIL. Unb, brasilia, 2014.

MILAGRES, B. S. Pesquisa de Rickettsia em animais sinantrópicos e domésticos em seus ectoparasitas em duas áreas de baixa endemicidade para febre maculosa brasileira da região leste de Minas Gerais, de 20052007. 2010. Tese (Doutorado) - Universidade Federal de Ouro Preto. Ouro Preto.

MONTEIRO, S.G., Parasitologia na medicina veterinária. Ed. 1 ed., São Paulo: ROCA 2010, p. 8-12. 2010.

OLIVEIRA, S. V. et al. An update on the epidemiological situation of spotted fever. Journal of Venomous Animals and Toxins including Tropical Diseases, Brasil, v. 22, p. 2-8, ago. 2016a.

OLIVEIRA, S. V. et al. Vigilância de ambientes da febre maculosa: explorando as áreas silenciosas do Brasil. Revista Pan-Amazônica de Saúde, v. 7, n. 3, p. 65-72, set. 2016b.

OLIVEIRA, S. V. Febre Maculosa no Brasil: Situação epidemiológica atual e a distribuição geográfica de carrapatos em cenários de mudanças climáticas. 2017. Tese (Doutorado) - Universidade da Brasília. Brasília.

REGNERY, R. L.; SPRUILL, C. L.; PLIKAYTIS, B. D. Genotypic identification of Rickettsiae and estimation of intraspecies sequence divergence for portions of two Rickettsial genes. Journal of Bacteriology, v. 173, n. 5, p. 1576-1589, 1991.

RIBEIRO, M.D.et al. FATORES AMBIENTAIS ENVOLVIDOS NA EPID'EMIOLOGIA DA FEBRE MACULOSA NO ESTADO DE SÃO PAULO. Revista Brasileira de Geografia Médica e da Saúde, São Paulo, 13 maio 2013. 
RODRIGUES, V. S. et, al; CARRAPATO-ESTRELA (AMBLYOMMA SCULPTUM): ECOLOGIA, BIOLOGIA, CONTROLE E IMPORTÂNCIA. Comunicado técnico 132. Brasília, 2015. Disponível em: < https://ainfo.cnptia.embrapa.br/digital/bitstream/item/134963/1/COT132Final.pdf > Acesso em: 17 out. 2020. 